vice president of $R \& D$ at Baxter Healthcare's unit in New Jersey-which is conducting Phase I trials using transgenic pig livers ex vivo as a bridge treatment for patients with severe acute liver failure-believes that "the benefits of using porcine livers to save lives while patients are waiting for transplants are tremendous and seem to far outweigh the risks."

The panel's mandate was to consider current knowledge on the risks of porcine endogenous retroviruses, including recent research indicating that a porcine endogenous retrovirus (PERV) is capable of infecting human cells in vitro.

Jonathan Allan, a virologist at the Southwest Foundation for Biomedical Research, Texas, and a member of the CBER subcommittee, told Nature Medicine that he strenuously urged that the FDA and Public Health Service be more cautious with respect to transplanting pig organs, which have until now been considered less risky than those of primates. "I'm not optimistic that the revised guidelines will be as stringent as necessary," says Allan.

The subcommittee also discussed laboratory assays and diagnostic procedures currently in development by the FDA to test for the presence of these viruses, and strategies for screening patient samples to prevent their transmission.

VICKI BRoWER, NEW YoRK

\section{CVI aims to speed products to market}

It takes between $15-20$ years from licensing a vaccine in an industrialized nation to its widespread use in less developed countries where it is most needed. However, the Children's Vaccine Initiative (CVI) hopes its new strategic plan, issued January 12 , will cut that timetable by a decade, according to Roy Widdus, coordinator of the

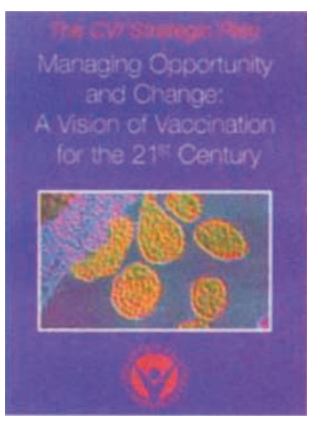
CVI. To do so, the group, a broad coalition sponsored by the World Bank, the World Health Organization, UNICEF, UNDP, and the Rockefeller Foundation, must convince developing nations to better recognize disease burden and to understand that vaccination is worth the investment, Widdus told Nature Medicine. Vaccination makes economic sense: ensuring that more children survive will create a larger pool of future "breadwinners," he says.

A spokeswoman for US pharmaceutical company Merck \& $\mathrm{Co}$ - one of the largest vaccine manufacturers in the worldagreed that a huge obstacle for vaccine makers is "that vaccines are undervalued" by many governments. She explained that it is tough to convince nations to purchase something such as the company's hepati-

\section{NIH opens top level biosafety facility}

The National Institutes of Health (NIH) is to become the third facility in the US to have a biosafety level-4 laboratory (BL-4), equipped to handle the most dangerous pathogens known. The $\$ 4.9$ million facility is scheduled to open early in 1998 . Currently, the Centers for Disease Control and Prevention (CDC) in Atlanta and the U.S. Army Medical Research Institute of Infectious Diseases (USAMRIID) in Maryland are the only such facilities in the country.

$\mathrm{BL}-4$ is the designation for the highest level of containment, and requires the most stringent security measures. However, unlike the CDC and USAMRIID labs, the NIH lab does not plan to investigate new disease outbreaks-at least not at the present time. Initial work will focus on drug-resistant strains of tuberculosis (TB) that pose a growing public health threat around the world. The increased research in this area comes in response to the global AIDS crisis, which has seen strains of TB flourish and to a 1991 US Congress order for NIH to accelerate its work on new TB strains. Around 2,000 people die from TB in the US each year and the disease infects 30 million people worldwide, killing three million every year.

Plans for similar labs in Canada and Japan have been opposed by local residents, but the reaction of the local Bethesda community outside Washington where NIH is located has been surprisingly low-key. This may be because NIH officials have stressed it is unlikely that the facility will become the focus for studying exotic or unidentified deadly agents. And in recent years, partly as a response to earlier clashes with the community over such issues as medical waste disposal, lighting and parking, $\mathrm{NIH}$ has opened up an aggressive dialogue with its neighbors to discuss mutual concerns. Ginny Miller, who chairs the Wyngate Citizens Association, which represents 1,640 households in the NIH neighborhood, agreed that residents are comfortable with the coming facility. "The NIH has been communicating with us, and I do think all our questions have been answered," she said.

Marlene Cimons, Washington, D.C. tis $B$ vaccine, when it may triple a country's entire vaccination budget.

Widdus acknowledges that scant resources are a factor in new product adoption, but he added, "the problems that hinder these new vaccines getting into use include money, but are not limited to money." The CVI strategic plan calls on governments to harmonize vaccine approval processes and improve intellectual property protection, which will encourage pharmaceutical companies to market vaccines worldwide.

CVI also hopes to convince manufacturers to develop products that are easier to administer-orally and in combination-and to build larger production capacity earlier in the vaccine development process. When a vaccine has been approved in an industrialized nation, the lack of an immediate and sizeable market means that there is typically a lag phase during which vaccine yield is increased and production quality is improved. But the CVI plan calls for that phase to be shortened so that demand in developing nations can be met more quickly.

CVI is already working with WyethLederle Vaccines to bring its oral rotavirus vaccine to needed areas once US Food and Drug Administration approval is granted. Obviously, the US is not the primary market for this vaccine, says Widdus. "We've had lots of discussions with WyethLederle about this and they recognize, as I think most of the American companies do, that the vaccine market is now a global one. They need to think beyond their traditional home base, which is a small volume market."

The CVI plan urges an increase in the deployment of existing vaccines, such as polio, hepatitis $B$, hemophilus influenza $b$, rubella and yellow fever. Full use of these vaccines could save up to four million lives a year, say CVI. The measles vaccine is the most under-used: CVI estimates that measles causes 1.1 million child deaths a year, half in sub-Saharan Africa.

Widdus is optimistic: "what we'll be able to do in the next decade or so is much, much more than we've done up to this point." But he warns, "to reap the benefit of the potential explosion of new vaccines, we have to do it in an organized, systematic fashion," adding that CVI aims to be the catalyst and coordinator of this effort.

Alicia Ault, Washington D.C. 